\title{
Perspectivas na contemporaneidade
}

Perspectivas em Ciência da Informação, ao longo dos últimos anos, vem procurando adequar-se aos novos paradigmas do processo de comunicação científica que, principalmente, a partir do último quartel do século passado, passou a interligar todo o planeta por meio das novas tecnologias da informação.

Nesse sentido, Perspectivas em Ciência da Informação implantou o Sistema Eletrônico de Editoração de Revistas - SEER - para o gerenciamento de suas atividades recebimento, avaliação e publicação dos artigos nos formatos impressos e eletrônico; foi selecionada para integrar a Coleção SciELO, alterou sua periodicidade para quadrimestral; e, a partir deste volume, II, número 3 , de dezembro de 2006, estará recebendo submissões de artigos que relatem resultados de pesquisas os quais, sendo aceitos, poderão ser publicados também nos idiomas espanhol, francês ou inglês.

Para o desenvolvimento destas ações, Perspectivas em Ciência da informação vem contando com o apoio do CNPq - Conselho Nacional de Desenvolvimento Científico e Tecnológico -, e da Pró-Reitoria de Pesquisa da UFMG, os quais são fundamentais para a continuidade da manutenção da revista nos dois formatos.

O presente fascículo inclui as seguintes seções:

\section{Artigos}

RedeCl: colaboração e produção científica em ciência da informação, no Brasil, de Fernando Parreiras, Antônio Silva, Renato Fabiano Matheus e Wladmir Brandão: apresenta a metodologia e os resultados preliminares da análise da co-autoria na área de ciência da informação no Brasil, realizadas por meio do uso da técnica de análise de rede social, como parte do projeto RedeCl.

Dissertações defendidas no Programa de Pós-Graduação em Ciência da Informação da UFMG, na década de 1990: um balanço, de Maria Yeda Falcão Soares de Filgueiras Gomes, caracteriza a produção acadêmica do curso de Mestrado em Ciência da Informação da UFMG, enfocando as tendências temáticas, tipos de pesquisa e abordagens metodológicas predominantes.

Periódico eletrônico Informação \& Sociedade: Estudos - impactos no contexto da comunicação científica, de Guilherme Atahide Dias, Eliany Alvarenga de Araújo, Joana Coeli Ribeiro Garcia e Alzira Karla Araújo da Silva, analisa os impactos provocados pelo acesso e pelo uso do periódico, em sua versão eletrônica.

Metodologia de elaboração de tesauro conceitual: a categorização como princípio norteador, de Maria Luiza Almeida Campos e Hagar Espanha Gomes, discute o surgimento do tesauro documentário como uma relação estruturada de termos constituídos, quase exclusivamente, de uma única palavra e sua evolução para algumas palavras compostas, sem estabelecer bases para isso.

Mapeamento de competências em bibliotecas universitárias, de Ângela Maria Oliveira, Eunice Silva Novais, Ivani Silva e Maria Luiza Fernandes Bertholino, apresenta um mapeamento de competências para identificar os conhecimentos, habilidades e atitudes existentes e necessárias ao staff da 
Biblioteca Central Prof. Faris Michaele da Universidade Estadual de Ponta Grossa - Paraná.

Educação continuada e mercado de trabalho: um estudo sobre os bibliotecários do Estado do Rio Grande do Norte, de Ana Cláudia Miranda, mostra a importância e a necessidade da educação continuada para os profissionais bibliotecários que atuam no Estado.

Biblioterapia para crianças em idade pré-escolar: estudo de caso, de Elaine R. de Oliveira Lucas, Clarice Fortkamp Caldin e Patrícia V. Pinheiro da Silva, busca identificar as contribuições da aplicação da biblioterapia em crianças em idade pré-escolar matriculadas em período integral no Centro de Educação Nossa Senhora da Boa Viagem.

Engenharia produz, a sociedade utiliza, de Cecília Prysthon, Suzane Schmidt e Murilo Silveira, estuda a criação e o repasse de tecnologias produzidas pelos cinco grupos de pesquisa de docentes/pesquisadores da área de engenharia civil da Universidade Federal de Pernambuco verificando a aplicabilidade e a repercussão das tecnologias junto ao segmento social. As pesquisas desenvolvidas revelam bom índice de retorno e benefício a problemas ambientais e de infra-estrutura da região.

\section{Revisões de literatura}

A administração da informação integrada às estratégias empresariais, de Joubert Roberto Ferreira Fidelis e Cristiane Missias Cândido, revisa e comenta os principais conceitos e atividades utilizados na gestão da informação nas organizações e o papel de prover às organizações meios de selecionar informação relevante aos seus negócios.

\section{Relatos de experiência}

Procedimentos básicos de seleção de documentos para conversão digital: elementos de atualização profissional em setores de duas instituições públicas federais, de Rubens Ribeiro Gonçalves da Silva, comenta os resultados de assessorias prestadas ao Centro de Memória e Documentação da Fundação Casa de Rui Barbosa e na Divisão de Informação e Prospecção Tecnológica do Instituto Nacional de Tecnologia, cujo elemento comum foi a elaboração e a realização de curso de atualização técnica sobre digitalização de acervos.

Perspectivas em Ciência da Informação espera continuar recebendo submissões de autores brasileiros escritos na língua pátria, e que professores, pesquisadores e profissionais da área de outros países enviem seus artigos em espanhol, francês ou inglês, para inclusão nos próximos fascículos.

Paulo da Terra Caldeira

Editor 